\title{
UBI SOCIETAS, IBI IUS? SOBRE EL LUGAR DEL DERECHO EN LAS TEORÍAS CLÁSICAS DEL PATRÓN CULTURAL UNIVERSAL
}

UBI SOCIETAS, IBI IUS? ABOUT THE PLACE OF THE LAW IN THE CLASSIC THEORIES OF THE UNIVERSAL CULTURE PATTERN

BENJAMÍN RIVAYA GARCÍA ${ }^{1}$

RESUMEN: No es infrecuente entre los antropólogos entender el Derecho como universal cultural. Que algún rasgo humano sea universal se puede explicar porque es natural, pero el Derecho no es natural. La pregunta entonces es si existen rasgos culturales, no naturales, universales, a lo que los antropólogos suelen responder afirmativamente. La otra pregunta sería la de si el Derecho es un universal cultural, lo que en buena medida depende del concepto de Derecho que utilicemos. No son pocos los antropólogos que, utilizando una perspectiva amplia sobre el Derecho, piensan que sí es un rasgo universal.

Palabras clave: Patrón cultural universal, antropología jurídica, concepto de Derecho, universales jurídicos.

ABSTRACT: Usually anthropologists understand the law as universal cultural. A human pattern can be universal because it is natural but the Law is not natural. Are there universal cultural patterns? Anthropologists tend to believe it. Is Law a cultural universal? It depends on the concept of Law that we use. Many anthropologists think that it is a universal culture pattern.

Keywords: Universal Culture Pattern, Legal Anthropology, Concept of Law, Legal Universals.

1 Catedrático de Filosofía del Derecho de la Universidad de Oviedo (España): rivaya@uniovi.es 
SUMARIO: I. La primera antropología y los universales culturales; II. El modelo sociocultural de Marx y Engels; III. La teoría del patrón cultural universal, de Clark Wissler; IV. La teoría del patrón cultural universal en manos del particularismo histórico: Boas, Benedict, Herskovits; V. La teoría del patrón cultural universal según Malinowski; VI. Cultura y personalidad y Derecho: Mead, Kluckhohn, Linton, Kardiner; VII. El estudio estadístico de los universales culturales: George P. Murdock; VIII. Los pre-requisitos parsonianos de la sociedad; IX. ¿Tiene el Derecho estructuras elementales universales? El patrón cultural universal según LéviStrauss; X. El patrón cultural universal del materialismo cultural: Marvin Harris.

C i la antropología es la ciencia humana por excelencia, no puede extrañar que interese a los demás investigadores so$\checkmark$ ciales, ya que de ella pueden obtener valiosas lecciones para sus estudios. Por lo que se refiere al Derecho, la antropología puede aportar nuevas perspectivas que el conocimiento jurídico tradicional/ convencional descuidó. ${ }^{2}$ La antropología que se ocupa con el Derecho, la política, los sistemas de control social, etc., es la antropología social o cultural, y en cuanto al orden jurídico, lo entiende como un producto social o como una parte de la cultura. Pero más allá de estas tópicas afirmaciones, la nueva ciencia social alumbra este y otros fenómenos con la luz de sus teorías sobre la naturaleza y la cultura humanas.

A primera vista, parece que la antropología que más nos interesa se dedica al estudio del Derecho primitivo o de los pueblos primitivos, probablemente en el entendimiento de que la comprensión de lo complejo, el Derecho de las sociedades avanzadas y de masas, exige previamente la comprensión de lo más simple. ${ }^{3}$ "Lo lógico sería - dijo Henry Sumner Maine- que empezáramos por el estudio

2 Fernanda Pirie, The Anthropology of Law. Oxford: Oxford University Press, 2013, 24.

${ }^{3}$ Michael Freeman y David Napier, eds., Law and Anthropology. Great Britain: Oxford University Press, 2009, 6. 
de las formas sociales más simples, en el estado más antiguo de su condición primitiva". ${ }^{4}$ Pero el Derecho primitivo interesa también por ser otro distinto al propio; raro, extraño. La antropología jurídica se ocupa sobre todo con el Derecho ajeno y entonces su problema es el de la comprensión de algo que, a primera vista, puede parecer incomprensible. ${ }^{5}$ No sorprende que los antropólogos hayan distinguido tradicionalmente entre una perspectiva interna, desde dentro, y otra externa, desde fuera, porque la visión cambia radicalmente según se utilice una u otra, y muchas veces optaron por el uso de ambas, primero la interna y luego la externa.

Por otra parte, la labor del etnógrafo que se dedica a la recopilación de los datos (jurídicos) de la cultura o del pueblo que estudia, aun siendo imprescindible, resulta insuficiente. La simple acumulación de noticias extrañas no conforma ninguna teoría. Además, los datos que se obtengan se encontrarán vinculados a una franja temporal determinada (sincronía) y especial importancia tiene el análisis del cambio temporal (diacronía), pues el primer estudio resulta demasiado estrecho, aunque a veces, al tenerse por representativo, se haya presentado como suficiente. El comparatismo propio de la disciplina antropológica lo explica: se trata de alcanzar conocimientos que sean fiables y, a la vez, lo más extensos posibles. Por eso, cuando se refiera al Derecho, importa observarlo más allá de los límites en los que habitualmente se investiga. Más que ciñéndose a este o aquel orden jurídico, importa comprenderlo dentro del marco del género humano y su desarrollo: ¿cómo se articula con el resto de la cultura?, ¿qué papel juega en el entramado social?, ¿qué elementos universales y qué otros particulares presenta?, ¿cómo evoluciona?, ¿con qué fin?, etc., etc. Se trata de la visión más amplia posible y, a la vez, apegada a la realidad.

4 Henry Sumner Maine, El Derecho antiguo. Madrid: Civitas, [1861] 1994, 85.

5 Franz von Benda-Beckmann, "Riding or Killing the Centaur? Reflections on the Identities of Legal Anthropology". En Freeman y Napier, Law and Anthropology, cit., 28. 
Si al principio la antropología se dedica al estudio del Derecho primitivo, al final de su trayecto se ocupa con una teoría omnicomprensiva del Derecho; una teoría que no descuide las diversas percepciones posibles, que tenga en cuenta tanto el Derecho más sencillo o los primeros rudimentos del Derecho, como el más complejo y desarrollado; que sea global, abstracta, de largo alcance. Por eso las teorías antropológicas del Derecho suelen resaltar el carácter adaptativo e integrador (o conflictivo y desintegrador) de éste, por encima de otras cuestiones más particulares. Su interés no es el estudio del orden jurídico como sistema autónomo, sino el del puesto y función que le corresponde dentro de la cultura toda, y el del papel que juega en el conglomerado social. Así, las teorías antropológicas del Derecho no suelen ser formalistas, porque ven el Derecho dentro del orden total de la sociedad y no como "un fenómeno autoconsistente y autosuficiente"; ${ }^{6}$ en otros términos, porque no suelen verlo como un sistema independiente que encuentra en sí mismo el fundamento de su validez. ${ }^{7}$ Léanse las palabras de Leopold J. Pospisil, que parecen referirse a Kelsen, cuando reniega de esa perspectiva del orden jurídico que lo ve como "un sistema legal lógicamente consistente y autónomo, en el que las distintas normas que lo integran son derivadas de otras más abstractas. Estas normas, integradas en una especie de pirámide, son fundamentadas en una norma básica o en una voluntad soberana". ${ }^{8}$

La antropología jurídica perfecta sería la que pudiera hacer que sus investigadores se integraran en un concreto pueblo y asumieran su Derecho y, acto seguido, se alejaran tanto de él que fueran capaces de verlo como un minúsculo mecanismo dentro de un en-

6 Csaba Varga, "Teorías macrosociológicas del Derecho", Anuario de Filosofía del Derecho V, 1988, 26.

7 Bronislaw Malinowski, "A New Instrument for the Interpretation of Law. Especially Primitive", The Tale Law Fournal 51, 1942: 1247.

8 Leopold Pospisil, Anthropology of Law. A Comparative Theory. New Haven: HRAF Press, 1974, 275. 
tramado gigante. El etnógrafo utilizaría primero el microscopio y, luego, el antropólogo se serviría del telescopio. En fin, las teorías antropológicas del Derecho son teorías macrosociológicas que tienen especialmente en cuenta la tradición doctrinal de la antropología social y cultural.

En este sentido, resulta de especial interés poner en relación el Derecho con un concreto tipo de doctrinas antropológicas, las que podemos denominar teorías del patrón cultural universal [TPCU], ${ }^{9}$ que relacionan y/o dan explicación de los rasgos universales de la cultura, del patrón cultural universal (universal culture pattern) [PGU], a consecuencia de su dedicación a la comparación entre culturas. ${ }^{10}$ Estas doctrinas, que se encuentran inevitablemente vinculadas a las teorías de la naturaleza humana, ${ }^{11}$ plantean dos cuestiones de gran

9 Tomo la expresión de Clark Wissler, pero también podría utilizarse la de George Murdock, "teoría del común denominador de las culturas" (Common Denominator of Cultures), o "teoría del consensus gentium", como la viene a llamar Clifford Geertz.

10 Para una aproximación a la historia de las TsPGU puede verse: Melville Herskovits, Cultural Relativism. Perspectives in Cultural Pluralism. New York: Vintage Books, 1973, 255-267; Clyde Kluckhohn, "Universal Categories of Culture". En Alfred L. Kroeber, ed., Anthropology Today. An Encyclopedic Inventory. USA: The University of Chicago Press, [1953] 1970; Robert Redfield, El mundo primitivo y sus transformaciones. México: FCE, 1963, 107-137; George Peter Murdock, Cultura y sociedad. 24 ensayos. México: Fondo de Cultura Económica, [1965] 1987, 85-105; J. Tennekes, Anthropology, relativism and method. An Inquiry into the Methodological Principles of a Science of Culture. Assen, Van Gorcum \& Co., 1971, 113-154; Harold E. Driver, "Cross-Cultural Studies". En John J. Honigman, ed., Handbook of Social and Cultural Anthropology. Chicago: Rand MacNally y \&, 1973, 327-367; Marvin Harris, El materialismo cultural. Madrid: Alianza Editorial, 1987, 63-67; D. E. Brown 1991: Human Universals. New York: McGraw-Hill, Inc., 1991, 54-88; Giovanni Cosi, Il logos del diritto. Torino: Giappichelli Editore, 1993, 159-178. Muy sintéticamente, Clifford Geertz, "The Impact of the Concept of Culture on the Concept of Man". En John R. Platt, ed., News Views of the Nature of Man. Chicago: The University of Chicago Press, 1970, 99-100.

11 Sobre la apasionante cuestión de la naturaleza humana, con todas las implicaciones jurídicas que puede tener, recomiendo de los últimos tiempos: Steven 
relevancia para la comprensión del Derecho: 1) Si el Derecho es un universal cultural y 2) cuáles son los rasgos universales del Derecho, lo que da lugar a las teorías que, por analogía, llamaremos del patrón jurídico universal, resultado de "la comparación intercultural de las instituciones jurídicas", ${ }^{12}$ teorías que conectan con el concepto de Derecho de gentes, entendido como mínimo común jurídico a todos los pueblos, y que quizás encuentran el último ejemplo más conocido en la teoría del contenido mínimo del Derecho natural, de H.L.A. Hart. Aunque inevitablemente aparezcan referencias al patrón jurídico universal, el objetivo de esta investigación consiste básicamente en observar el lugar del Derecho en las teorías del patrón cultural universal, es decir, responder a la pregunta acerca de si el jurídico es un elemento universal de la cultura, para lo que resulta evidente que la cuestión del concepto de Derecho que manejaron los antropólogos se vuelve crucial, como que estos científicos sociales suelen utilizar un criterio amplio; más amplio, en cualquier caso, que el de los juristas, que habitualmente defienden una concepción legalista del Derecho con la que los antropólogos no se sienten a

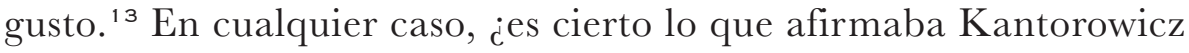
en 1958, que la entonces moderna antropología se mostraba "incapaz de descubrir sociedades, por primitivas y carentes de carácter estatal que fueran, desprovistas de Derecho"? 14

Pinker, La tabla rasa. La negación moderna de la naturaleza humana. Barcelona: Paidos, [2002] 2016; Jesús Mosterín, La naturaleza humana. Madrid: Austral, 2006.

12 Martha Mundy, ed., Law and Anthropology. Great Britain: Ashgate/ Dartmouth, 2002, XVI.

${ }^{13}$ Leopold Pospisil, The Ethnology of Law. Menlo Park: Cummings Publishing, 1978, 18-19.

14 Hermann Kantorowicz, La definición del Derecho. Madrid: Revista de Occidente, [1958] 1964, 48. 
Aunque también sea cierto que muchos antropólogos han estado obsesionados con la explicación de las diferencias culturales, ${ }^{15}$ las TsPGU aparecieron con la antropología. Que las culturas presentan similitudes y equivalencias, rasgos comunes, es un conocimiento intuitivo que captará cualquiera que se dedique a su estudio. De hecho, los primeros antropólogos lo destacaron prontamente. Ahora bien, si el nacimiento de la nueva ciencia estuvo ligado al evolucionismo, ¿acaso también el evolucionismo reconoce un patrón universal? Con la evolución, ¿no cambia la cultura toda, de tal forma que se convierte en un conjunto de elementos particulares en cada caso? Precisamente tanto Tylor como Morgan y Spencer, los padres de la ciencia antropológica, evolucionistas los tres, se ocuparon con la cuestión de los universales de la cultura.

El caso de Tylor nos interesa especialmente, pues dedicó a esta problemática el primer capítulo de su Primitive Culture. Como es sabido, la obra se abre con la más clásica definición de cultura:

Tomada en su amplio sentido etnográfico, es ese complejo conjunto que incluye el conocimiento, las creencias, las artes, la moral, las leyes, las costumbres y cualesquiera otras aptitudes y hábitos adquiridos por el hombre como miembro de la sociedad. ${ }^{16}$

Así Tylor estaba apuntando una TPCU, en el sentido de que señalaba un conjunto de rasgos universales, estando entre ellos el jurídico, rasgos que aparecerían en cualquier cultura conocida o por conocer. Pero ¿el PGU de Tylor se compadecía con su evolucionismo? Es cierto que dijo que en toda cultura había aspectos uniformes y otros variables: mientras los primeros se mantenían, eran los segundos los que evolucionaban y, por tanto, los que nos in-

15 Robin Fox, The Search for Society. Quest for a Biosocial Science and Morality. London: Rutgers University Press, 1989, 15.

16 Edward B. Tylor, Cultura primitiva. Madrid: Ayuso, [1871] 1977, 19. 
dicaban en qué fase de la evolución se hallaba la cultura que fuera. Pero refiriéndose al Derecho en concreto, tuvo que reconocer que hubo un tiempo en que no existió, cuando sólo había la venganza, y que iría "apareciendo gradualmente". ${ }^{17}$ Conclusión: el Derecho no habría existido siempre, pero quizás una vez que apareció ya quedó instalado en la cultura y se convirtió en universal. Surge así una pregunta que nos acompañará a lo largo de este trabajo: ¿por qué una invención o creación humana, cultural por tanto, se vuelve universal? En cualquier caso, propuso algo interesante a todos los que quisieran estudiar la cultura, incluido el Derecho, mirarlos desde lejos:

Cuando desde una montaña miramos un ejército, olvidamos al soldado individual, al que, en realidad, apenas podemos distinguir en la gran masa, mientras vemos cada regimiento como un cuerpo organizado, que se dispersa o que se concentra, que avanza o que retrocede. ${ }^{18}$

En cuanto a Lewis H. Morgan, a quien en gran medida Engels le daría fama, destaca por su periodificación de la cultura, que partiendo de un estadio inferior de salvajismo arribaría, tras pasar por otro de barbarie, al de la civilización. Esa evolución, además, valdría para cualquier cultura. Sin embargo, tal periodificación no implicaba que entre uno y otro estadio no hubiera ningún parecido, sino que en los diversos momentos se darían soluciones distintas a ciertas cuestiones universales: ${ }^{19}$

1. Subsistencia.

2. Gobierno.

3. Lenguaje.

17 Edward B. Tylor, Antropología. Introducción al estudio del hombre y la civilización. Barcelona: Editorial Alta Fulla, [1881] 1987, 489.

18 Tylor, Cultura primitiva, cit., 27.

19 Lewis H. Morgan, La sociedad primitiva. Madrid: Ayuso, [1877] 1975, 78-89. 
4. Familia.

5. Religión.

6. Vida de hogar y arquitectura.

7. Propiedad.

Morgan no incluía el Derecho en el esquema universal que proponía. Probablemente de su evolucionismo pudiera colegirse que el fenómeno jurídico aparecía en algún momento del desarrollo cultural, no en el inicio de éste. Así, expresamente dijo que "la ley internacional, codificada y consuetudinaria" y la "ley civil" surgen con la civilización; ${ }^{20}$ aunque por otra parte también afirmó expresamente que los "gérmenes de las instituciones principales" ya aparecieron en el periodo del salvajismo, ${ }^{21}$ lo que quizás permitiría hablar de un Derecho primitivo.

En cuanto a Spencer, al comienzo de sus Principios de Sociología vino a establecer un PCU. Explicó qué elementos habría que describir para conocer una sociedad, estando entre ellos el Derecho. Habría que exponer las condiciones ecológicas y climáticas en que vivía el pueblo que fuera; la población, sus características y modificaciones; el trabajo llevado a cabo y su impacto sobre el medio; la organización de la sociedad; el influjo de la sociedad sobre los individuos; la relación con las sociedades vecinas; la guerra, factor operativo de primer orden; la organización política; la organización industrial; la tecnología; el lenguaje; la ciencia; los productos estéticos: las "costumbres cada vez más numerosas y estereotipadas que conducen a los sistemas de legislación”. ${ }^{22}$ Quizás esto último quería decir que el Derecho moderno sólo existía en las sociedades más avanzadas, aunque las primitivas estarían dotadas de otro

20 Morgan, La sociedad primitiva, cit., 100.

21 Morgan, La sociedad primitiva, cit., 81.

22 Herbert Spencer, Abreviatura de principios de sociología. Buenos Aires: Revista de Occidente, 1947, 17-19. 
consuetudinario, primitivo. Algo parecido se observa si se analiza la forma de resolución de los conflictos, según Spencer, pues en los pueblos primitivos se encontraría una "grosera administración de justicia" que habitualmente utiliza la venganza y que se acabaría transformando en una "administración pública de la justicia", ${ }^{23}$ lo que de nuevo serviría para distinguir entre un Derecho primitivo y otro Derecho a secas.

\section{iI. El modelo sociocultural de Marx y Engels}

El patrón cultural universal del marxismo fue descrito en una cita clásica de la Contribución a la crítica de la economía política, donde Marx estableció un mapa de los fenómenos culturales sobre el que aplicar la metodología materialista, el principio del determinismo económico:

El conjunto de estas relaciones de producción constituye la estructura económica de la sociedad, la base real sobre la cual se eleva la superestructura jurídica y política y a la que corresponden formas sociales determinadas de conciencia. El modo de producción de la vida material condiciona el proceso de vida social, política e intelectual en general. No es la conciencia de los hombres la que determina la realidad; por el contrario, la realidad social es la que determina su conciencia [...] El cambio que se ha producido en la base económica trasforna más o menos lenta o rápidamente toda la colosal superestructura. ${ }^{24}$

Aunque se trata de una presentación sintética del PCU que requeriría desarrollo y problematización, de la aplicación de ese mapa sobre cualquier sociedad se obtendría (a los ojos de un marxista) una visión cabal de la misma. Si efectivamente se trata de una versión de la TPCU, eso significaría que el Derecho, la superestruc-

23 Herbert Spencer, La justicia. Buenos Aires: Atalaya, 1947, 180.

24 Karl Marx, Contribución a la crítica de la economía política. Granada: Comares, [1859] 2004, XXXI. 
tura jurídica, es un elemento universal, que existiría en cualquier sociedad. Pero ¿efectivamente postularon Marx y Engels que toda sociedad tiene Derecho?

No lo creo. En El origen de la familia, de la propiedad privada y el estado, Engels hizo una descripción de la evolución de la humanidad, para lo que utilizó, además de la periodificación de Morgan, la distinción entre sociedad gentilicia y estatal; contando aquélla con la sola opinión pública como medio coercitivo, mientras que ésta utilizará ya la forma legal. ${ }^{25}$ Evolucionistas como Marx y Engels no suelen creer que el Derecho exista desde el inicio de los tiempos; al contrario, es normal que vean su nacimiento en un determinado momento de esa evolución. Entonces, la expresión "superestructura jurídica y política" no habría que traducirla como "Derecho y Estado" sino, más ampliamente, como "organización social", lo que no requiere necesariamente ni del Derecho ni del Estado. De hecho, de aquél se podría predicar lo mismo que Engels predicó de éste, con lo que la cita pasaría a decir: "el Derecho no ha existido eternamente. Ha habido sociedades que se las arreglaron sin él, que no tuvieron la menor noción del Derecho ni de su Poder. Al llegar a cierta fase de desarrollo económico que estaba ligada necesariamente a la división de la sociedad en clases, esta división hizo del Derecho una necesidad". ${ }^{26}$

ili. La teoría del patrón cultural universal, de Clark Wissler

Pero quien acuño la expresión de "patrón cultural universal" fue Clark Wissler, en una obra que alcanzaría reconocimiento, Man and Culture (1923). En ella, además de elaborar importantes conceptos

25 Friedrich Engels, El origen de la familia, la propiedad privada y el Estado. Madrid: Ediciones Endymión, [1884] 1988, 171-172.

26 Engels, El origen de la familia, la propiedad privada y el Estado, cit., 177. 
para la antropología, como el de "área cultural” y "área temporal", Wissler defendió que por cultura había que entender el modo de vida de un pueblo, y que si bien era cierto que las maneras de vivir variaban, también lo era que algunos procesos y estructuras resultaban constantes. Aunque tal vez sus palabras no fueran muy precisas, resultaba que las culturas diferían en sus contenidos, pero se asemejaban en sus formas. A esa semejanza fue a la que llamó "patrón universal", y al conjunto de rasgos culturales universales lo denominó "esquema de cultura". En éste incluyó los siguientes elementos: ${ }^{27}$

1. Habla

1.1. Idiomas, sistemas escritos, etc.

2. Rasgos materiales

2.1. Hábitos alimenticios

3.2. Refugio

4.3. Transporte

5.4. Vestido

6.5. Utensilios, herramientas, etc.

7.6. Armamento

8.7. Ocupación e industria

3. Arte, escultura, pintura, dibujo, música, etc.

4. Mitología y conocimientos científicos.

5. Prácticas religiosas

5.1. Formas rituales

27 Clark Wissler, Man and Culture. New York: Thomas Y. Crowell, [1923] 1965, 73-97. 
6.2. Tratamiento de la enfermedad

7.3. Tratamiento de la muerte

8. Familia y sistema social

6.1. Formas de matrimonio

7.2. Método de relación

8.3. Herencia

9.4. Control social

10.5. Deportes y juegos

11. Propiedad

7.1. Real y personal

8.2. Reglas de valor e intercambio

9.3. Comercio

10. Gobierno

8.1. Formas políticas

9.2. Procedimientos judiciales y legales

10. Guerra

Visto desde hoy, el listado de Wissler resulta incompleto y confuso, pero su gran mérito no se encontró tanto en la relación de los elementos comunes cuanto en el hincapié que puso en éstos; en su insistencia en los rasgos universales de la cultura. Por supuesto, el afán ya había comenzado. Habría que perfeccionar la lista y, a la vez, plantearse cuáles eran los rasgos universales de cada uno de esos rasgos universales: de la lengua, de la religión o del Derecho, entre otros. En referencia al elemento jurídico, por cierto, cabría entenderlo incluido dentro del control social, pero hacía expresa referencia a los "procedimientos judiciales y legales", lo que habitualmente se entiende por Derecho, en el epígrafe de gobierno. Como 
había hecho Marx, también Wissler situó el fenómeno jurídico al lado del político.

IV. LA TEORÍA DEL PATRÓN CULTURAL UNIVERSAL EN MANOS DEL PARTICUlARISMO histórico: BoAs, Benedict, Herskovits

Realmente Clark Wissler era un seguidor de Franz Boas, el padre del particularismo histórico, una de las tendencias doctrinales más importantes de toda la historia de la antropología. El particularismo histórico nació como corriente enfrentada al evolucionismo, y vinculada al neokantismo de Dilthey, Windelband y Rickert. El fundador, Boas, aunque no despreciara los análisis nomotéticos, generalistas, demostraba sentir preferencia por los idiográficos o particularistas, lo que trajo consigo un aumento considerable del trabajo de campo y un mayor rigor en las descripciones de los pueblos que estudiaron sus seguidores. Pero Boas no podía ser insensible a las similitudes culturales que encontró por todos lados. En su obra más conocida, The Mind of Primitive Man, partió de reconocer la enorme variedad de las diferencias culturales, pero luego parecía asombrado porque idénticos fenómenos se repitieran en zonas muy alejadas del globo". ${ }^{28}$ Sobre todo destacó las similitudes morales. Él mismo formuló una teoría del contenido mínimo de la moral: "Es un deber de toda persona respetar la vida, el bienestar y la propiedad de los demás, y evitar cualquier acción que pueda dañar al grupo como un todo. Todas las infracciones de este código serán sancionadas con castigos sociales o sobrehumanos". ${ }^{29} \mathrm{Y}$ del contenido mínimo del Derecho, pues reconoció que en las normas jurídi-

28 Franz Boas, The Mind of Primitive Man. New York: Dover Publications, [1911] 1963, 149-161.

29 Franz Boas, Anthropology and Modern Life. New York: Dover Publications, [1928] 1962, 225. 
cas se repetían monótonamente unas cuantas ideas básicas. ${ }^{30}$ Pero también afirmó con carácter general que, aunque hubiera rasgos universales, éstos "se manifestaban con específicas formas en cada sociedad". ${ }^{31}$ Uno de sus discípulos más afamados, la antropóloga Ruth Benedict, radicalizó las ideas del maestro y abrazó con fuerza el relativismo cultural, pero a la vez tuvo que reconocer que las sociedades humanas poseían rasgos universales o casi universales, y señaló dos, el animismo y las limitaciones que la exogamia imponía al matrimonio. ${ }^{32}$

Pero entre los discípulos de Boas, quien más contribuyó a la elaboración de una TPGU fue Melville Herskovits, aunque sobre todo sea conocido por su defensa a ultranza del relativismo cultural. ${ }^{33}$ Para Herskovits lo que verdaderamente tiene carácter universal es la cultura, mientras que en cada sociedad se adopta una forma particular de ésta. Ahora bien, al ser universal la cultura también lo son los elementos que ella abarca: un modo de subsistencia, un equipamiento tecnológico, un sistema de distribución de los productos, una organización de la familia y el parentesco, algún tipo de control político, una filosofía de la vida y una religión, un sistema estético, un lenguaje. Luego los organizó en los siguientes epígrafes: ${ }^{34}$

зо Franz Boas, Race, Language and Culture. New Yotk: The Free Press [1940] 1968, 271.

31 Boas, Anthropology and Modern Life, cit., 61-62.

32 Ruth Benedict, El hombre y la cultura. Barcelona: Edhasa, [1934] 1989, 30.

зз Resulta llamativo el parecido entre la postura relativista de Herskovits y la de uno de los teóricos del Derecho más importantes de la historia, Hans Kelsen, pues ambos seguían del relativismo el valor de la tolerancia. En palabras de Herskovits: "el relativismo cultural es una filosofía que, al reconocer los valores que establece cada sociedad para guiar su propia vida, insiste en la dignidad inherente a cada cuerpo de costumbres y en la necesidad de tolerancia frente a convenciones diferentes de las nuestras"; en Melville Herskovits, Cultural Relativism. Perspectives in Cultural Pluralism. New York: Vintage Books 1973, 90-92.

34 Herskovits, Cultural Relativism. Perspectives in Cultural Pluralism, cit., 30-31 y 265-266. 
1. Cultura material y sus sanciones

1.1. Tecnología

1.2. Economía

2. Instituciones sociales

2.1. Organización social

3.2. Educación

4.3. Estructuras políticas

3. El hombre y el universo

3.1. Sistemas de creencias

4.1. El control del poder

4. Estética

4.1. Artes pictóricas y plásticas

5.2. Folklores

6.3. Música, drama y danza

5. Lenguaje

Desde la perspectiva relativista de Herskovits era importante subrayar que la universalidad de los elementos culturales, sobre todo la de los valores, no quería decir que tuvieran un carácter absoluto. Que hubiera valores absolutos significaría que serían fijos y estables, y que no admitirían variación, mientras que afirmar su universalidad sólo implicaría que entre ellos habría un denominador común, de tal forma que podría utilizarse el mismo término para designarlos: en todas partes se reconocen ciertos valores, pero no hay "dos culturas cuyas instituciones sean idénticas en la forma", dijo. El resultado era que los universales, producto de la inducción, 
siempre tenían un carácter abstracto, genérico, incluso vago. ${ }^{35}$ En fin, la moralidad era universal, pero los concretos sistemas morales eran distintos, "producto de la particular experiencia histórica de las sociedades donde se manifiestan”. ¿Cabría decir lo mismo del Derecho? Probablemente. Herskovits se ocupó con la cuestión del concepto de Derecho para criticar a los juristas que, creyéndose en posesión de la verdad, utilizaban una definición muy estrecha y etnocéntrica. Reconocía que se trataba de un problema, pero optaba por ensanchar la categoría de lo jurídico; por tener en cuenta, a la hora de llevar a cabo un análisis comparativo del Derecho, "las instituciones empleadas para efectuar fines semejantes en otras sociedades"; por reducir la importancia de la estructura y ampliar la de la función. ${ }^{36}$ Pero quien con ideas semejantes a las expuestas integró el Derecho en el PGU fue, sin duda, Bronislaw Malinowski.

V. LA TEORÍA DEL PATRÓN CULTURAL UNIVERSAL SEGÚN MALINOWSKI

La importancia de la antropología social británica para la antropología del Derecho resulta enorme, hasta el punto de que la polémica que se produjo entre Malinowski y Radcliffe-Brown sirve aún hoy día para distinguir entre el Derecho identificado funcionalmente, que es un "universal sociocultural", y el Derecho formalmente considerado, que "no está universalmente presente en todas las sociedades". ${ }^{37}$

Ahora nos interesa sobre todo Bronislaw Malinowski, cuyo Crime and Custom in Savage Society (1926) no sólo es la obra más clásica de esta rama de la etnología sino una joya del pensamiento jurídico

35 Herskovits, Cultural Relativism. Perspectives in Cultural Pluralism, cit., 91 y 259.

36 Melville Herskovits, El hombre y sus obras. México: FCE, [1948] 1952, 363, 378-379.

37 J. M. Donovan y H. E. Anderson, Anthropology E̊ Law. New York: Berghahn, $2003,12$. 
todo. Pero tenemos que empezar refiriéndonos a su teoría de la cultura, para ver si en ésta se incardina el Derecho de forma universal, es decir, si forma parte o no del PGU que propone Malinowski. Curiosamente, se le encargó la voz "Culture" de la Encyclopaedia of the Social Sciences, que se publicaría en 1931, y allí dijo que se trataba de la "herencia social" que incluía "artefactos, bienes, procedimientos técnicos, ideas, hábitos y valores", y si bien es verdad que en la definición no aparecía el término Derecho (Law), ni siquiera el de normas o reglas, más adelante advertía que la cultura no se agotaba sólo en la economía, el Derecho y la educación, ${ }^{38}$ con lo que se evidenciaba que éste formaba parte de aquélla.

En cuanto a cómo acercarse a la cultura con el objeto de conocerla, Malinowski afirmaba de forma tajante que "funcionalmente", esto es, concibiéndola como un medio para satisfacer una necesidad. ${ }^{39}$ Entonces, a su juicio, funcionalista era el análisis con el que se intentaba "definir la relación entre un comportamiento cultural y una necesidad humana, básica o derivada". ${ }^{40}$ Desde este punto de vista ocurría que toda creación cultural tenía una finalidad a la que se dirigía y que resultaba ineludible conocer ésta para dilucidar en qué consistía aquélla. Ahora bien, había un fin último al que la cultura toda estaba encaminada, "el de la supervivencia biológica", de tal manera que ya fuera el Derecho, el arte, la cocina o la electricidad, en último término todas esas realidades se dirigían a que el hombre sobreviviera. Su teo-

38 Bronislaw Malinowski, "La cultura". En J. S. Kahn, ed., El concepto de cultura. Textos fundamentales. Barcelona: Anagrama, [1931] 1975, 85-107.

39 Estoy persuadido de que la teoría de las necesidades de Malinowski se encuentra en el origen de la teoría del contenido mínimo del Derecho natural, de H.L.A. Hart. No deja de llamar la atención que en El concepto de Derecho (Buenos Aires, Abeledo-Perrot, [1961] 1977, 306) Hart citara el cásico de Piddington, "Malinowski's Theory of Needs" en referencia a la distinción entre punto de vista interno y externo, cuando sería más congruente que lo citara en relación a la teoría del contenido mínimo del Derecho natural.

40 Bronislaw Malinowski, Una teoría cientifica de la cultura. Madrid: Sarpe, [1944] $1984,116,89$ y 59 . 
ría de la cultura se basaba, dijo, en hechos biológicos. ${ }^{41}$ Pero ¿a quién se refería Malinowski cuando hablaba de la supervivencia, al individuo o al grupo? Hay razones para pensar que el antropólogo partió de una idea individualista con la que no logró dar explicación de todo lo que analizaba, por lo que la reelaboró en un sentido societario. De hecho, al abordar la cuestión de las necesidades primeras, las entendió como aquellas condiciones de diverso tipo, tanto ambientales como biológicas, que han de satisfacerse "para la supervivencia del individuo y del grupo", y más adelante, al volver sobre el tema, dijo que las necesidades que él tenía en cuenta no eran individuales sino sociales y culturales. ${ }^{42}$

Pero importa destacar la tabla de necesidades que Malinowski elaboró, pues era ese elenco el que explicaba toda la cultura. En pocas palabras, son el hambre, el sexo y la salud, los problemas naturales con que el hombre se enfrenta y para resolverlos construye muy diversas herramientas culturales. A su vez, la cultura crea nuevas necesidades ("un tipo secundario de determinismo") que también ha de satisfacerse culturalmente y así de forma sucesiva. Ésta era la tabla:

\section{Tabla 1.}

\begin{tabular}{ll}
\hline Necesidades básicas & Respuestas Gulturales \\
\hline a) Nutrición & a) Aprovisionamiento \\
b) Reproducción & b) Parentesco \\
c) Bienestar corporal & c) Abrigo \\
d) Seguridad & d) Protección \\
e) Movimiento/relajación & e) Actividad/reposo \\
f) Crecimiento & f) Aprendizaje \\
g) Salud & g) Higiene \\
\hline
\end{tabular}

41 Malinowski, Una teoría cientifica de la cultura, cit., 30 y 56.

42 Malinowski, Una teoría científica de la cultura, cit., 97 y 111. 
Es cierto que el listado es susceptible de críticas, pero lo que importa ahora es fijarse en las respuestas culturales que merecen las necesidades básicas y cómo se satisfacen éstas, por medio de un instrumental diverso que incluye herramientas, reglas técnicas, normas y valores.

En cuanto a las necesidades o "imperativos culturales" ya sabemos que, según Malinowski, derivan de las otras y que son una conditio sine qua non para que no se produzca "la destrucción o el conflicto en sentido biológico". A su juicio, estas necesidades se pueden sintetizar así:

\section{Tabla 2.}

\begin{tabular}{ll}
\hline NECESIDADES Culturales & Respuestas culturales \\
\hline a) Formas de producción y & a) Economía \\
consumo & \\
b) Formas de comportamiento & b) Control social \\
c) Formas de conocimiento & c) Educación \\
d) Formas de autoridad & d) Política \\
g) Salud & g) Higiene \\
\hline
\end{tabular}

De tal manera, lo que Malinowski consigue es diversificar entre necesidades de derivación inmediata y de derivación remota. Ahora bien, la diferencia que se observa entre ellas es su mayor o menor desarrollo, es decir, que la economía, el control social, la educación y la política representarían - creo yo- una fase más avanzada de institucionalización en la manera de satisfacer las necesidades primeras. ${ }^{43}$ Mas ¿dónde se encuentra el Derecho?

Mientras otros autores daban por sobreentendido el concepto de Derecho, Malinowski reflexionó sobre él y no sólo utilizó uno sino dos concepto distintos. Aunque no suela tenerse en cuenta,

43 Malinowski, Una teoría científica de la cultura, cit., 142-153. 
a veces lo entendió como una normatividad respaldada por una organización de la coacción y por tribunales, lo que le llevó a reconocer que no todas las sociedades primitivas tenían Derecho, ${ }^{44}$ es decir, que no sería una institución universal, existente en cualquier cultura. Pero habitualmente mantuvo una idea mucho más amplia y difusa de Derecho, minimizando sus componentes estructurales y centrándose en el aspecto funcional, en el control social que ejerce. En Crime and custom dijo que las normas jurídicas se caracterizaban por dos notas: porque establecían derechos y obligaciones, y porque se hallaban respaldadas por "una definida maquinaria social de poderosa fuerza obligatoria" basada en la reciprocidad. ${ }^{45}$ Además se centró en las funciones que cumplía: "contener ciertas propensiones naturales, canalizar y dirigir los instintos humanos e imponer una conducta obligatoria no espontánea; con otras palabras, asegurar un tipo de cooperación basado en concesiones mutuas y en sacrificios orientados hacia un fin común". ${ }^{46}$ Así se difuminaba aún más la estructura del Derecho. Por fin, en los comentarios que hizo al libro de Llewellyn y Hoebel, The Cheyenne Way, que aparecieron al poco de su muerte en Yale Law fournal, lo dejó claro: "El Derecho no es un fin en sí mismo, sino un instrumento indispensable para alcanzar los fines reales, en última instancia biológicos, del obrar humano". ${ }^{47}$ En fin, aunque no citara expresamente el Derecho en su patrón cultural, en su relación de universales culturales, éste se integraba bajo el rótulo de control social y existía en cualquier cultura.

44 Malinowski, Una teoría científica de la cultura, cit., 137 y 151.

45 Bronislaw Malinowski, Crimen y costumbre en la sociedad salvaje. Barcelona: Ariel [1926] 1991, 65-74.

46 Malinowski, Crimen y costumbre en la sociedad salvaje, cit.79-80.

47 Bronislaw Malinowski, "A New Instrument for the Interpretation of Law. Especially Primitive", The Tale Law Fournal 51, 1942, 1245. 
vi. Cultura y personalidad y derecho: mead, Kluckhohn, Linton, Kardiner

Conectado también con el particularismo histórico de Boas y aunque demostrara la singularidad de algunos fenómenos que se habían tenido por universales, la corriente de Cultura y Personalidad se interesó por la TPCU. Es cierto que el centro de su estudio fue el del influjo que la cultura tiene en la formación de la personalidad de los individuos, pero eso no impidió que se interesara también por los rasgos culturales comunes, sobre todo por los valores, a veces aplicados al Derecho.

Por ejemplo Margaret Mead se dedicó básicamente al estudio de la manera en que los papeles se reparten entre los sexos en las distintas culturas, pero no menospreció las similitudes que halló entre los diferentes pueblos. En este sentido, resulta de sumo interés un estudio antropológico que dedicó no al Derecho sino al Derecho natural, nada menos, "Some Anthropological Consideratios Concerning Natural Law”, en el que afirmaba algo que a un jurista occidental le podía resultar sorprendente, que cada cultura reconocía un peculiar Derecho natural, es decir, que el Derecho natural era universal, pero no porque sus contenidos lo fueran, sino porque en todos los sitios se reconocía, aunque fuera con contenidos diversos. Así todo, Mead decía que las similitudes culturales eran tan persistentes que sólo podían ser explicadas por la unidad del género humano. En concreto, era normal que hubiera semejanzas entre las culturas, porque todas ellas se integraban dentro del sistema de supervivencia de la especie. Por lo que toca al Derecho natural, no el de cada pueblo sino otro constituido por preceptos y principios que todo orden jurídico necesariamente acogía, señaló la universalidad de tres instituciones de enorme importancia: el homicidio, el incesto y la propiedad privada.

Además Mead apuntó dos cuestiones de interés. Por un lado una de carácter lógico, que del hecho de que esas normas y principios 
se encontraran en todas las sociedades del presente y del pasado no se seguía que fueran a encontrarse también en las del futuro (lo que también podría decirse del Derecho). Por otra, y más allá de la estricta lógica, que parecía razonable que esos preceptos y principios, una especie de código ético mínimo, se mantuvieran en toda cultura, pues las sociedades no parecen viables sin ellos. "Así, el Derecho natural puede ser definido como un conjunto de reglas de comportamiento que aparece en todas las sociedades conocidas y que se ha desarrollado a partir de la capacidad moral de una especie específica, la humana". ${ }^{48}$

Pero dentro de Cultura y personalidad fue Clyde Kluckhohn quien más se ocupó con el asunto de los universales antropológicos y, en particular, con la universalidad de ciertos valores que interesan al Derecho, lo que hizo decir a Clifford Geertz que se trataba "quizás del más persuasivo de los teóricos del consensus gentium". ${ }^{49}$ En Mirror for Man (1949) ya lo dejó apuntado: todas las sociedades humanas se encuentran ante las mismas necesidades que resolver, necesidades impuestas por la biología y por la concreta situación vivida, lo que explica que los elementos básicos de todas las culturas sean muy parecidos, al menos mirados en abstracto: el lenguaje, algún tipo de pensamiento, la regulación de la actividad sexual, etc. En concreto, empero, sus variaciones son "innumerables", decía. Lo curioso es que afirmó que "no todas las culturas fomentan la supervivencia física", que por tanto ésa no era la razón de los parecidos, razón que parecía encontrar en la supervivencia de la sociedad y la adaptación de los individuos. ${ }^{50}$ En lo tocante a los valores, con buen sentido

48 Margaret Mead 1961: "Some Anthropological Considerations Concerning Natural Law". Natural Law Forum 6: 51-54.

49 Clifford Geertz, "The Impact of the Concept of Culture on the Concept of Man”. En John R. Platt, ed., New Views of Nature of Man, Chicago: The University of Chicago Press, 1970, 100.

50 Clyde Kluckhohn, Antropología. Madrid: Fondo de Cultura Económica, $1974,34-43$. 
afirmó que la antropología no negaba la existencia de valores absolutos y, con menos razón, creyó que esos absolutos podían ser descubiertos por medio del método comparado, capaz de descubrir los rasgos morales inevitables. "Todas las culturas reconocen algunas de las mismas formas de comportamiento como patológicas", es decir, que habría conductas universalmente incorrectas. ${ }^{51}$ Eso sí, frente a los excesos universalistas, en la misma obra apuntó un dato que no por sabido tenía menos importancia, el de la plasticidad de la naturaleza de los seres humanos, capaces de idear las soluciones más diversas para un mismo problema. Advertía así contra aquellos que, frente a lo nuevo, exclamaban: "eso no funcionará nunca, es contrario a la naturaleza humana". Ahora bien, el reconocimiento de esa plasticidad no significaba que no hubiera valores morales absolutos. A su juicio los había; incluso se podría encontrar su fundamento científico: $:^{52}$

Algunos valores parecen ser tan dados por la naturaleza como el hecho de que los cuerpos más pesados que el aire caen. Ninguna sociedad ha aprobado nunca el sufrimiento como una cosa buena por sí misma; como un medio para los fines de la sociedad, sí. No tenemos que confiar en la revelación sobrenatural para descubrir que el intercambio sexual conseguido por medio de la violencia es malo. Esto es un hecho de observación general, en la misma medida que el hecho de que diferentes objetos tienen diferentes densidades. La observación de que la verdad y la belleza son valores humanos universales y trascendentales es una de las cosas dadas de la vida humana, en la misma medida que el nacimiento y la muerte.

Entre la cultura y la naturaleza no habría la ruptura que muchos proclamaban: "Hay un cierto orden en la naturaleza, y el lenguaje

51 Lo que recuerda la afirmación de H.L.A. Hart cuando decía, valiéndose de un título de Robert Louis Stevenson, que la sociedad no es un club de suicidas (El concepto de Derecho, cit., 238), lo que significaría que, efectivamente, hay conductas que para cualquier sociedad serían patológicas.

52 Kluckhohn, Antropología, cit., 52 y 283-303. 
y los valores forman parte de esa categoría de la naturaleza, a saber, de la cultura". ${ }^{53}$

Posteriormente Kluckhohn, en algún caso junto con Kroeber, perfilaría más su postura. Siguió explicando la universalidad de ciertos fenómenos culturales por las necesidades, tanto individuales como sociales - dijo ahora-, que tenían que satisfacer. En este sentido, había hechos que requerían algún tipo de tratamiento, muchas veces inevitablemente parecido: la existencia de dos sexos, la necesidad de ayuda que tienen las crías humanas, la necesidad que todo el mundo siente de satisfacer ciertos requerimientos biológicos (alimento, abrigo, sexo), la diferencia por grupos de edad, etc. No sería extraño, por tanto, que hubiera valores universales. Ahora bien, entonces Kluckhohn tuvo que reconocer, de acuerdo con Herskovits, que no era lo mismo afirmar que un valor era universal que decir que era absoluto. Sin embargo, Kluckhohn creía que el hecho de que un valor fuera universal era un dato que indicaba una tendencia a lo absoluto, lo que le valía para repudiar el relativismo cultural a lo Benedict. Por otra parte, de acuerdo con Mead reconoció que el que un valor fuera universal, en el pasado y el presente, no significaba que lo fuera a seguir siendo en el futuro. Aunque también era cierto - dijo- que la persistencia de ciertos rasgos culturales a lo largo de toda la historia de la humanidad, hacía pensar que se hallaban arraigados en la naturaleza humana "y/o" eran condiciones necesarias para la vida social. En fin, parecía que tenía sentido hablar de la naturaleza humana, lo que hacía que las culturas fueran distintas y semejantes a la vez y, por lo tanto, comparables. ${ }^{54}$

53 Clyde Kluckhohn, "Towards a Comparison of Values-Emphases in Different Cultures". In Leonard D. White, ed., The State of the Social Sciences. Chicago: The University of Chicago Press, 1965, 118.

54 Alfred Kroeber y Clyde Kluckhoh, Culture. A Critical Review of Concepts and Definitions. Cambridge (USA): Harvard University Press, 1952, 174-179; Kluck- 
Había, por tanto, patrones morales universales que clasificó: a) normas que permiten o prohíben concretos comportamientos, como la que ordena decir la verdad o la que prohíbe el incesto, la violencia o el robo dentro del grupo y b) principios generales, con un gran nivel de abstracción, que tienden a asegurar la estabilidad y la continuidad del grupo, así como a maximizar la satisfacción de la experiencia individual. ${ }^{55}$ Pero aunque esas normas, principios y valores tuvieran que ver con el fenómeno jurídico, Kluckhohn no se refirió al Derecho en concreto, ausente de su TPGU.

Otro miembro destacado de Cultura y Personalidad, ${ }^{56}$ Ralph Linton, vino a decir que los universales humanos eran ciertas necesidades biológicas, sociales y psíquicas que cada cultura se había ocupado de satisfacer a su manera. ${ }^{57}$ La pregunta que cabría hacerse sería si acaso la necesidad no moldeaba la forma de satisfacerla; su respuesta fue terminante: "la necesidad da forma a la respuesta cultural, pero ésta, a su vez, da forma a la necesidad". En alguna medida, por tanto, aunque adoptaran presentaciones diversas, había reglas universales, las que se enfrentaban al cumplimiento de las necesidades universales. Es más, es que las reglas también eran universales; toda sociedad tenía sus reglas, sin que pudiera ser de otra forma, pues se componía por un conjunto de individuos, un sistema de

hohn, "Towards a Comparison of Values-Emphases in Different Cultures", cit., 286-300; Kluckhohn, Antropología, cit., 1970: 519-522.

55 Kluckhohn, "Towards a Comparison of Values-Emphases in Different Cultures", cit., 278.

56 Hubo más. Abram Kardiner, un psicoanalista metido a antropólogo, también vino a pergeñar una TPGU. A su juicio habría varios rasgos universales: familia, grupos más amplios, técnicas para la subsistencia, disciplinas básicas, control de la agresión mutua, control psicológico, finalidad de la vida; en El individuo y su sociedad: la psicodinámica de la organización social primitiva. México: FCE, 1945, 31-32.

57 Ralph Linton, Estudio del hombre. México: Fondo de Cultura Económica, [1932] 1972, 381-383 y 398-399. 
normas y un patrimonio de ideas y valores que precisamente son la "fuerza motriz" de aquellas normas. ${ }^{58}$

No sólo las normas entendidas como pautas de conducta, al margen de su contenido, eran universales sino que algunas normas concretas, con un determinado contenido, también eran universales, como la que dice que en ninguna sociedad el asesinato es la conducta correcta. ${ }^{59}$ Del Derecho no dijo que fuera universal, pero sí de la ética o la moral, a la vez que había "principios éticos universales", aseguró, lo que era debido a las características biológicas y psicológicas de los hombres, así como a la propia necesidad de supervivencia de la humanidad. Resaltó un dato de enorme interés, que para llevar a cabo el análisis comparativo necesario, las unidades significativas eran "las sociedades, no los individuos"; luego se dedicó a apuntar pautas morales universales. Las había en lo relativo al sexo, la familia, la economía y la propiedad, y a las relaciones entre los miembros de una sociedad. ${ }^{61}$ En fin, del Derecho no dijo que fuera universal, pero de su discurso se seguían ciertas consecuencias para todo orden jurídico, una vez que apareciese.

ViI. El estudio estadístico de los universales culturales: George P. Murdock

Frente a las tendencias al análisis idiográfico del material antropológico, propias de quienes se adherían al particularismo histórico, sobre todo en los Estados Unidos en el primer tercio del siglo XX,

58 Linton, Estudio del hombre, cit., 104 y 116.

59 Ralph Linton, The Science of Man in the World Crisis. New York: Columbia University Press, 1945, 202-204; Estudio del hombre, cit., 398-400.

60 Ralph Linton, "Universal Ethical Principles: An Anthropological View". En Ruth Nanda, ed., Moral Principles of Action. Man's Ethical Imperative. New York: Harper \& Brothers, 1952, 648.

61 Linton, "Universal Ethical Principles: An Anthropological View", cit., 651-660. 
avanzada la década de los treinta George Peter Murdock desarrolló una corriente de signo contrario, nomotético, que pretendía lograr todo el rigor posible para los resultados de un método comparativo y generalizador. Su gran logro sería, sin duda, la introducción de la estadística en el estudio de los datos etnológicos, lo que se plasmó en el grandioso proyecto del Cross-Cultural Survey, y luego los Human Relations Area Files. En los archivos que se organizaron probablemente se encuentra el mayor registro que nunca haya existido de las diferentes culturas y, por tanto, inauguraban una época nueva para el método comparativo, que así se alejaba de cualquier tipo de especulación. En fin, Murdock vino a revitalizar la TPGU. ${ }^{62}$

En un artículo que apareció en 1940 en la American Sociological Rewiev, Murdock indicó cuáles eran los caracteres propios de la cultura. A su juicio la cultura era aprendida, inculcada, social, ideal, productora de satisfacciones (en el doble sentido de que satisface necesidades y produce más placer que dolor), adaptativa e integradora. Es curioso que tras citar cada uno de esos rasgos, el autor concluyera afirmando que en todas las culturas tenían que existir caracteres comunes, principio del que partía: "la convicción de que todas las culturas humanas, a pesar de su diversidad, tienen fundamentalmente mucho en común, y que esos aspectos comunes pueden analizarse científicamente" ${ }^{63}$ Así cuando afirmó que toda cultura era social, lo que significaba que sus hábitos eran compartidos por los miembros de una sociedad y que se mantenían por medio de la presión social, dijo que eso había de significar que en cualquier sociedad tenían que darse unos rasgos culturales que también existirían en las demás, supuesto que se encargaran de la supervivencia de la sociedad. "Entre estos universales culturales, probablemente

62 Ya en Social Structure (New York: The Free Press, 1965, XV) probablemente su obra más acabada, Murdock reconocía la deuda que había contraído con Clark Wissler.

63 George Peter Murdock, "The Cross-Cultural Survey". American Sociological Review V, 3, 1940, 364. 
podemos mencionar cosas tales como los sentimientos de cohesión del grupo, los mecanismos de control social, la organización para la defensa contra los vecinos hostiles y la provisión de alimentos para la perpetuación de la población". ${ }^{64}$

Posteriormente, en "El común denominador de las culturas" (1945), ofreció una TPGU, tras constatar que los antropólogos se habían dedicado más a subrayar las diferencias que existen entre las culturas, que a relacionar sus semejanzas. Empezó por detallar, por orden alfabético, los rasgos culturales universales: ${ }^{65}$

Adiestramiento en la limpieza, adivinación, adorno corporal, alimentos tabúes, arte decorativo, baile, calendario, cirugía, comercio, concepto de alma, control del tiempo climático, cortejo de las mujeres, cosmología, costumbres del embarazo, costumbres de la pubertad, cuidado posnatal, curación por la fe, chistes, dar regalos, deportes atléticos, derechos de propiedad, destete, diferenciación de rangos, división del trabajo, división por edades, educación, escatología, estilos de peinados, ética, etiqueta, etnobotánica, fabricación de herramientas, familia, fiestas, folklore, formas de guisar, gestos, gobierno, grupos de parientes, hacer fuego, higiene, horas de comer, hospitalidad, interpretación de los sueños, juegos, lenguaje, leyes, luto, magia, matrimonio, medicina, mitología, modestia (respecto a las funciones naturales), música, nombres personales, nomenclatura de los parentescos, numerales, obstetricia, organización de la comunidad, política de la población, propiciación de los seres sobrenaturales, restricciones sexuales, reglas de residencia, ritos funerarios, ritos religiosos, saludos, sanciones penales, supersticiones sobre la muerte, tabúes del incesto, trabajo corporativo, visitas, vivienda.

64 Murdock, "The Cross-Cultural Survey", 365.

65 George Peter Murdock, Cultura y sociedad. 24 ensayos. México: Fondo de Cultura Económica, [1965] 1987, 86. Si se observa la descripción que Murdock hace de los pueblos primitivos (Nuestros contemporáneos primitivos. México: FCE, [1934]1975), se constata que el listado de rasgos universales es un buen modelo de lo que debe ser descrito. 
Las categorías universales que Murdock destacaba, sin embargo, tenían en cada cultura un contenido específico. En todas existían derechos de propiedad, pongo por caso, pero en ninguna eran iguales. En todas había restricciones sexuales, pero nunca eran exactamente las mismas. Lo mismo cabría decir de las leyes, que tendrían distintos contenidos; aunque lo que llama la atención es que dijera de éstas que eran universales, lo que significaría que el Derecho es un universal de la cultura; claro que quizás haya quien piense que se trataba de un uso excesivo del término: el Derecho de los tasmanianos, pueblo ya desaparecido, era completamente rudimentario; los semang de Malaya carecen de algo que se parezca a las leyes formales; los kazacos del Asia central desconocen cualquier formalidad jurídica, etc. ${ }^{66}$

Pero hay que advertir que los rasgos no eran tanto universales per se, cuanto por obra del investigador que, con buen criterio, los agrupaba bajo una misma rúbrica: derechos de propiedad o restricciones sexuales o leyes, por ejemplo. Entonces, el PGU era el resultado de un proceso abstractivo que culminaba en un concepto relativamente formal. Entre todos los productos culturales, o al menos entre muchos de ellos, había similitudes y diferencias, y se podía optar por poner el acento en unas o en otras. Ahora bien, si se reparaba en las semejanzas, habría que interesarse por su razón de ser y ésta sólo se podía encontrar - dijo- "en la naturaleza biológica y psicológica fundamental del hombre y en las condiciones universales de la existencia humana".

Murdock recurrió a los principios del aprendizaje para explicar los universales de la cultura. A su juicio, los impulsos básicos, los estímulos y la habitualidad servían para entender por qué se producían aquéllos. Pero hay un factor más que nos interesa especialmente, el que llamó "limitaciones en la gama de respuestas potenciales". Al igual que en el caso del aprendizaje, la cultura no

66 Murdock, Nuestros contemporáneos primitivos, cit., 19, 86, 128. 
puede tener cualquier contenido, sencillamente porque hay ciertas circunstancias limitadoras que lo impiden (ecológicas, biológicas, psíquicas, estructurales, etc.). En ciertos casos, las limitaciones son muy débiles; por ejemplo ocurre con el lenguaje, que puede optar por términos variadísimos para designar el mismo objeto. En otros, en cambio, las restricciones son mayores, con lo que las posibilidades se restringen más; por ejemplo en lo relativo a la normativa del parentesco - dijo--, que sólo puede escoger entre tres posibles criterios: paterno, materno o bilateral. Por fin, en el caso extremo sólo hay una posibilidad y no cabe opción posible. Como ejemplo, Murdock puso el de la familia nuclear (padre, madre, hijos): "El hombre nunca ha podido encontrar un sustituto adecuado para la familia y todos los intentos utópicos para abolirla han fracasado espectacularmente". ${ }^{67}$ Aplicado al Derecho, el principio de la limitación en la gama de respuestas potenciales significaba la negación de un postulado del positivismo, el que dice que el Derecho puede tener cualquier contenido.

\section{LOS PRE-REQUISITOS PARSONSIANOS DE LA SOCIEDAD}

En 1950, en la revista Ethics apareció un artículo firmado por varios sociólogos norteamericanos, "The Functional Prerequisites of a Society", artículo que, en la órbita del pensamiento parsonsiano, estaría llamado a crear un debate de enorme interés en el que participaría un buen número de antropólogos. De hecho, para el ala izquierda de la ciencia social resultó tan escandaloso que pronto empezaron a escucharse voces acusándolo de conservador, cuando no de reaccionario. Sea como fuere, el polémico trabajo trataba de determinar cuáles eran las condiciones necesarias de cualquier sociedad, sus prerrequisitos funcionales, de tal forma que si faltaban éstos, aquélla se tornaría imposible. En otras palabras, también

67 Murdock, Cultura y sociedad. 24 ensayos, cit., 100-104. 
Aberle, Cohen, Davis, Levy y Sutton, los autores, presentaban una TPCU, aunque advirtieran que no era ni mucho menos definitiva y que podría ampliarse por medio de los estudios de sociología comparada al uso. Además, una teoría completa también requeriría de la perspectiva estructural y ellos, conscientemente, no la tenían en cuenta.

La posibilidad que estos funcionalistas utilizaban era la de la destrucción o desaparición de una sociedad. La posibilidad era real, claro, y se produciría - decían- en alguno de los siguientes supuestos: 1) En el caso de extinción biológica o dispersión de sus miembros, en un número significativo, que convierta en "inoperativa su estructura de acción”. 2) En el caso de apatía o pérdida de motivación de sus miembros, de nuevo en un número significativo. 3) En el caso de que estallara la guerra de todos contra todos. 4) En el caso de absorción de una sociedad por otra (1950:103-104). ${ }^{68}$

De esta forma, para evitar la extinción de la sociedad que fuera, sería necesario que en ella se cumplieran ciertas condiciones pues, en caso contrario, sucumbiría. Estos prerrequisitos funcionales de la sociedad serían: ${ }^{69}$

1. Que existan medios para que se produzca una adecuada integración de la sociedad con el entorno, y para la reproducción ["sexual recruitment"], lo que se concretaría en "un número suficiente de adultos para garantizar la reproducción y conserva el status quo".

2. Que haya reglas de diferenciación y reparto de tareas.

3. Que exista comunicación.

4. Que haya orientaciones cognitivas compartidas.

68 D. F. Aberle, A. K. Cohen, A. K. Davis, M. J. Levy y F. X. Sutton, "The Functional Prerequisites of a Society". Ethics LX, 1950, 103-104.

69 Aberle, Cohen, Davis, Levy y Sutton, cit., "The Functional Prerequisites of a Society", cit., 104-110. 
5. Que exista un conjunto articulado y compartido de metas sociales.

6. Que haya alguna regulación compartida de los medios existentes para lograr los fines deseados.

7. Que haya alguna regulación de la expresión afectiva.

8. Que exista alguna forma de socialización (educación).

9. Que se controlen los comportamientos problemáticos y conflictivos, sobre todo la violencia arbitraria y el fraude.

Algunos de los otros también, pero sobre todo este último requisito tenía mucho que ver con el Derecho, aunque no aparecía expresamente en el listado que proponían. Como siempre, que el Derecho fuera o no un rasgo universal dependía de que se utilizara un concepto más o menos amplio.

En cualquier caso, en clave funcionalista, estos sociólogos creían poder contribuir a la construcción de una teoría social general que, aplicada a concretos casos, sirviera para alcanzar un mejor conocimiento de particulares sociedades. Ahora bien, no es difícil adivinar por qué fue tan criticada esta doctrina: el armonicismo que pretendía resultaba excesivo. Tanto quienes sólo se fijan en los elementos conflictivos como quienes sólo se dan cuenta de los armonizadores no son capaces de construir una doctrina completa de la sociedad.

El uso del concepto de solidaridad social por Saint-Simon, Comte y Durkheim se inserta en una línea ininterrumpida de teorías políticamente conservadoras que enlaza directamente con las principales variedades del funcionalismo entre los antropólogos sociales contemporáneos, británicos, franceses y americanos. Mientras la ciencia social radical seguía a Marx en el estudio de lo que se necesitaba para que el organismo social se disgregara, los conservadores como Spencer, Durkheim, Radcliffe-Brown y Malinowski se ocupaban de 
calcular las razones de que mantuvieran su cohesión. Admitamos que ambos intereses son legítimos (Harris 1987a: 404). ${ }^{70}$

No sólo ambos intereses son legítimos, sino que los dos son necesarios si se quiere construir una teoría social convincente. En cualquier caso, no se referían expresamente al fenómeno jurídico.

\section{IX. ¿TIENE EL DERECHO ESTRUCTURAS ELEMENTALES UNIVERSALES? EL PATRÓN CULTURAL UNIVERSAL SEGÚN LEVI-STRAUSS}

En cierta forma podría decirse que el estructuralismo es una TPCU, pues se ocupa de analizar las realidades culturales, buscando "elementos invariables entre diferencias superficiales". ${ }^{71}$ Tales elementos invariables, estructuras mentales universales, constituirían el PCU pero, dicho esto, el objetivo se torna difícil.

El conjunto de las costumbres de un pueblo es marcado siempre por un estilo; dichas costumbres forman sistemas. Estoy persuadido de que esos sistemas no existen en número ilimitado y de que las sociedades humanas, como los individuos -en sus juegos, sus sueños o sus delirios- jamás crean de manera absoluta sino que se limitan a elegir ciertas combinaciones en un repertorio ideal que resultaría posible reconstruir. Si se hiciera el inventario de todas las costumbres observadas $[\ldots]$ se llegaría a una especie de tabla periódica como la de los elementos químicos. ${ }^{72}$

Al igual que el aparato vocal de los seres humanos permite emitir ciertos sonidos pero no otros, de tal forma que el lenguaje es una opción entre un conjunto de sonidos finitos, las instituciones tam-

70 Marvin Harris, El desarrollo de la teoría antropológica. Una historia de las teorías de la cultura. Madrid: Siglo XXI de España editores, [1968] 1987, 404.

71 Claude Lévi-Strauss, Mito y significado. Madrid: Alianza Editorial, [1978] 1995, 26-31.

72 Claude Lévi-Strauss, Tristes trópicos. Barcelona: Paidós, [1955] 1992, 85. 
bién son limitadas. "Cada tipo de organización social representa, en consecuencia, una elección que el grupo impone y perpetua"73. Esos modelos, esas estructuras, se encuentran tanto en la mente de los nativos como de los científicos sociales que estudian las instituciones. ${ }^{74}$ Aplicado al Derecho, ocurriría lo mismo que con los mitos, por ejemplo, que tomados en conjunto, todos paran en lo mismo y, como lo afirma Goethe de las plantas, "su coro guía hacia una ley oculta" ${ }^{75}$ y así no sería fantasioso pensar que los métodos lévi-straussianos podrían encontrar en el estudio de los órdenes jurídicos un nuevo campo de pruebas. ${ }^{76}$ Sin embargo, hasta donde sé, el empeño no ha dado demasiados frutos. Aunque la de norma fuera una estructura universal, ${ }^{77}$ el Derecho no lo era, ni hasta donde sé han sido encontradas estructuras jurídicas universales, si es que existen.

\section{El PATRón CULTURAL universal DEL MATERIALismo cultural: Marvin Harris}

Una corriente antropológica de singular interés es la del materialismo cultural, que encuentra en Marvin Harris a su más autorizado representante. Para éste, el patrón universal no se reduce a una exposición de los rasgos pan-humanos y pan-societarios, sino que también abarca las relaciones que se establecen entre ellos, de tal manera que, conforme a la opción nomotética que profesa y al

73 Claude Lévi-Strauss, Las estructuras elementales del parentesco. Barcelona: Paidós, [1949] 1991, 126-138.

74 Claude Lévi-Strauss, El futuro de los estudios de parentesco. Barcelona: Anagrama, 1973, 62 .

75 Claude Lévi-Strauss, El hombre desnudo. Mitológicas IV. México: Siglo XXI Editores, [1971] 1997, 626.

76 André-Jean Arnaud, "Structuralisme et droit", Archives de Philosophie du Droit XIII, 1968, 285.

77 Lévi-Strauss, Las estructuras elementales del parentesco, cit., 125. 
principio del determinismo infraestructural, se podrían llegar a formular las leyes científicas que rigen el desenvolvimiento humano. ${ }^{78}$

Por un lado, Harris reconoce las constantes bio-psíquicas de la especie humana, si bien se aleja de cualquier reduccionismo biológico y, al reconocer la especial plasticidad del ser humano, restringe aquéllas al máximo. Dicho con sus palabras, éstos son los rasgos naturales (y, por tanto, universales) de los seres humanos: ${ }^{79}$

1. Las personas necesitan comer y, por regla general, optarán por las dietas que ofrezcan más calorías, proteínas y otros nutrientes.

2. Las personas no pueden permanecer completamente inactivas, aunque a la hora de enfrentarse a una tarea específica, preferirán realizarla consumiendo el mínimo de energía.

3. Las personas poseen una sexualidad muy desarrollada y obtienen un placer reconfortante en el coito (heterosexual en la mayor parte de las ocasiones).

4. Las personas necesitan amor y afecto para sentirse felices y seguras y, a igualdad de las demás cosas, harán lo posible para aumentar el amor y afecto que les brindan los demás.

Evidentemente, es tal la importancia de estos rasgos, que aparecen constantemente cuando se quiere interpretar casi cualquier realidad cultural. Empero, aunque deban ser tenidos en cuenta, por sí solos son incapaces de otorgar una explicación satisfactoria, explicación que es la que ofrecería la teoría del materialismo cultural. Además de que resulte necesario distinguir entre pensamiento y conducta, y las perspectivas emic (interna, del participante) y etic

78 Harris, El desarrollo de la teoría antropológica. Una historia de las teorías de la cultura, cit., 569.

79 Marvin Harris, El materialismo cultural. Madrid. Alianza Editorial, [1979] $1987,79$. 
(externa, del científico), Harris dibuja un mapa de cualquier cultura, mejorando el que había elaborado Marx, que como ya vimos distinguió entre la estructura económica, la superestructura jurídico política y la conciencia social. Para el materialismo cultural, en cambio, éste sería el patrón cultural universal: ${ }^{80}$

1. Infraestructura.

1.1. Modo de producción

1.2. Modo de reprocucción

2. Estructura

2.1. Economía política

3.2. Economía doméstica

3. Superestructura

3.1. Conductual etic

4.2. Mental emic

Expuesto sintéticamente el mapa sociocultural del materialismo cultural, el principio que convierte esta metodología en materialista es el determinismo infraestructural, que luego Harris pasó a llamar "primacía de la infraestructura", que significa en cualquier caso que es la infraestructura la que determina la estructura y la superestructura, si bien ésta es una regla general probabilística que puede tener excepciones; de hecho, "las teorías materialistas culturales pueden invocar diferentes grados de causación infraestructural, que oscilan entre la certeza y la indeterminación casi absolutas". ${ }^{81}$

Por medio de los elementos infraestructurales se ofrece solución a los problemas básicos que cualquier sociedad debe resolver, el

80 Harris, El materialismo cultural, cit., 67-70.

81 Harris, El desarrollo de la teoría antropológica. Una historia de las teorías de la cultura, cit., 67-93. 
de la producción de los bienes materiales (tecnología, relaciones tecno-ambientales, etc.) y el de la reproducción de la población (medios de control de la natalidad, emigración/ inmigración, etc.). Se da así respuesta a las preguntas de cuántos son los miembros y cuánta riqueza tiene la sociedad que sea. En cuanto a los elementos estructurales, las economías domésticas y política, significan la organización de facto de la producción y la reproducción, así como la organización del intercambio y el consumo, ya sea en el ámbito doméstico (estructura familiar, división del trabajo doméstico, etc.) o en el político (organización política, sistema de clases, etc.). Se da así respuesta a la pregunta de cómo se reparten los bienes entre los miembros de la sociedad. Por fin, los elementos superestructurales satisfacen una necesidad psíquica humana e incluyen (superestructura conductual etic) productos y servicios rituales, recreativos, estéticos, etc. así como (superestructura mental emic) las creencias, valores, planes de vida, filosofías, etc. Se contesta así a la pregunta de cómo se explica y cómo se justifica (en general, todo, cualquier realidad; entre otras cuestiones, la fundamental del reparto de los bienes). El Derecho no se encuentra como tal en este plano o mapa sociocultural, es decir, no es universal, no existió siempre; si bien, una vez que surge, el Derecho real, el Derecho en acción, forma parte sobre todo de la economía política (policías, jueces, cárceles, etc.), pero visto desde su dimensión ritual (los ritos legislativos y judiciales) pertenecería a la superestructura conductual-etic y visto desde su dimensión normativa (normas, principios y valores), a la superestructura ideal-emic.

El Derecho no habría existido siempre pero probablemente hoy esté en todos lados. ¿Por qué? En principio, la respuesta de Harris parece clara: hay rasgos universales que, sin embargo, son culturales, lo que se debe a que son "tan útiles que se transmiten de unas culturas a otras o se inventan o reinventan sin parar". ${ }^{82}$ Que sean

82 Marvin Harris, Nuestra especie. Madrid: Alianza Editorial, [1989] 1997, 183. 
útiles, sin embargo, no quiere decir que sean morales; de hecho Harris sigue en buena medida a Marx, es decir, relaciona el Derecho con el "monopolio de los instrumentos de coerción por parte de una clase dominante", ${ }^{83}$ lo que querría decir que la presión de la clase dominante, la principal beneficiaria del Derecho, sería un factor fundamental para su mantenimiento y expansión. Eso no quiere decir que el Derecho no pueda ser un instrumento beneficioso para las clases subordinadas o para la sociedad toda, pero siempre que también beneficie, y habitualmente beneficiará más, a las clases dominantes. ${ }^{84}$

\section{Xi. Bibliografía}

Aberle, D. F., Cohen, A. K., Davis, A. K., Levy, M. J. y Sutton, F. X., “The Functional Prerequisites of a Society". Ethics LX, 1950: 100-111. Arnaud, André-Jean, "Structuralisme et droit". Archives de Philosophie du Droit XIII, 1968: 283-301.

Benda-Beckmann, Franz von, "Riding or Killing the Centaur? Reflections on the Identities of Legal Anthropology". Freeman \& Napier 2009: 13-46.

Benedict, Ruth, El hombre y la cultura. Barcelona: Edhasa, [1934] 1989.

BoAs, Franz, Anthropology and Modern Life. New York: Dover Publications [1928] 1962.

- The Mind of Primitive Man. New York: Dover Publications, [1911] 1963.

- Race, Language and Culture. New Yotk: The Free Press, [1940] 1968. Brown, D.E., Human Universals. New York: McGraw-Hill, Inc., 1991.

Cosi, Giovanni, Il logos del diritto. Torino: Giappichelli Editore, 1993.

83 Harris, El materialismo cultural, cit., 253.

84 Marvin Harris, Introducción a la antropología general. Madrid: Alianza Editorial, [1975] 1992, 430. 
Donovan, James M. y H. Edwin Anderson, Anthropology \& Law. New York: Berghahn, 2003.

Driver, Harold E. "Cross-Cultural Studies". En John J. Honigman, ed., Handbook of Social and Cultural Anthropology. Chicago: Rand MacNally y \&, 1973.

EngeLs, Friedrich, El origen de la familia, la propiedad privada y el Estado. Madrid: Ediciones Endymión, [1884] 1988.

Fox, Robin, The Search for Society. Quest for a Biosocial Science and Morality. London: Rutgers University Press., 1989.

Freeman, Michael, y David Napier, eds., Law and Anthropology. Great Britain: Oxford University Press, 2009.

Geertz, Clifford, "The Impact of the Concept of Culture on the Concept of Man", en John R. Platt, ed., New Views of Nature of Man, Chicago. The University of Chicago Press, 1970.

HARris, Marvin, El desarrollo de la teoría antropológica. Una historia de las teorías de la cultura. Madrid: Siglo XXI de España editores, [1968] 1987.

—_, El materialismo cultural. Madrid. Alianza Editorial, [1979] 1987.

-, Introducción a la antropología general. Madrid: Alianza Editorial, [1975] 1992.

—, Nuestra especie. Madrid: Alianza Editorial, [1989] 1997.

Hart, H.L.A., El concepto de Derecho. Buenos Aires: Abeledo-Perrot, [1961] 1977.

Herskovits, Melville, El hombre y sus obras. México: FCE., [1948] 1952.

- Cultural Relativism. Perspectives in Cultural Pluralism. New York: Vintage Books, 1973.

Kantorowicz, Hermann [1958] 1964: La definición del Derecho. Madrid: Revista de Occidente [1958] 1964.

Kardiner, Abram, El individuo y su sociedad: la psicodinámica de la organización social primitiva. México: FCE, 1945.

Kluckhohn, Clyde, "Towards a Comparison of Values-Emphases in Different Cultures". En Leonard D. White, ed., The State of the Social Sciences. Chicago: The University of Chicago Press, [1956] 1965. 
—_, "Universal Categories of Culture". En Alfred L. Kroeber, ed., Anthropology Today. An Encyclopedic Inventory. USA: The University of Chicago Press, [1953] 1970.

—, Antropología. Madrid: Fondo de Cultura Económica, [1949] 1974.

Kroeber, Alfre y Clyde Kluckhohn, Culture. A Critical Review of Concepts and Definitions. Cambridge (USA): Harvard University Press, 1952.

Lévi-Strauss, Claude, El futuro de los estudios de parentesco. Barcelona: Anagrama, 1973.

- Claude, Las estructuras elementales del parentesco. Barcelona: Paidós, [1949] 1991.

— Claude, El hombre desnudo. Mitológicas IV. México: Siglo XXI, [1971] 1997.

— Claude, Tristes trópicos. Barcelona: Paidós, [1955] 1992.

—, Claude, Mito y significado. Madrid: Alianza Editorial, [1978] 1995.

Linton, Ralph, The Science of Man in the World Crisis. New York: Columbia University Press, 1945.

— , "Universal Ethical Principles: An Anthropological View". In Ruth Nanda, ed., Moral Principles of Action. Man's Ethical Imperative. New York: Harper \& Brothers, 1952.

- Estudio del hombre. México: Fondo de Cultura Económica, [1932] 1972.

Maine, Henry Sumner, El Derecho antiguo. Madrid: Civitas, [1861] 1994.

Malinowski, Bronislaw, "A New Instrument for the Interpretation of Law. Especially Primitive”, The Yale Law Journal 51, 1942: 1237-1254.

—, "La cultura" [1931]. En J. S. Kahn, ed., El concepto de cultura. Textos fundamentales. Barcelona: Anagrama, 1975.

—, Una teoría científica de la cultura. Madrid: Sarpe, [1944] 1984.

- Crimen y costumbre en la sociedad salvaje. Barcelona: Ariel, [1926] 1991.

Marx, Karl, Contribución a la crítica de la economía política. Granada: Comares, [1859] 2004.

Mead, Margaret, "Some Anthropological Considerations Concerning Natural Law". Natural Law Forum 6, 1961: 51-64. 
Morgan, Lewis H., La sociedad primitiva. Madrid: Ayuso, [1877] 1975.

Mosterín, Jesús, La naturaleza humana. Madrid: Austral, 2006.

Mundy, Martha, ed., Law and Anthropology. Great Britain: Ashgate/ Dartmouth, 2002.

Murdock, George Peter, "The Cross-Cultural Survey". American Sociological Review V, 3, 1940: 361-370.

—, Nuestros contemporáneos primitivos. México: FCE, [1934] 1975.

- Cultura y sociedad. 24 ensayos. México: Fondo de Cultura Económica [1965] 1987.

Pinker, Steven, La tabla rasa. La negación moderna de la naturaleza humana. Barcelona: Paidós, [1965] 1987.

PIRIE, Fernanda, The Anthropology of Law. Oxford: Oxford University Press, 2013.

Pospisil, Leopold J., The Ethnology of Law. California: Cummings Publishing Company, 1974.

- The Ethnology of Law. Menlo Park: Cummings Publishing, 1978.

REDFIELD, Robert, El mundo primitivo y sus transformaciones. México: FCE, 1963.

Rivaya, Benjamín, "Una teoría científica del Derecho. El pensamiento jurídico de Bronislaw Malinowski”. Sociologia del Diritto 1, 1998.

— , "Estructura y función en el Derecho primitivo. El pensamiento jurídico de Radcliffe-Brown”. Sociologia del Diritto 2, 2001.

—_, "Las estructuras elementales del Derecho. El pensamiento jurídico de Lévi-Stauss". En Juan Antonio García Amado, ed., El Derecho en la teoría social. Diálogo con catorce propuestas sociales actuales. Dykinson: Madrid, 2001.

—- El materialismo jurídico. La presunta teoría del Derecho de Marvin Harris. Madrid: Dykinson, 2007.

Spencer, Hebert, Abreviatura de principios de sociología. Buenos Aires: Revista de Occidente, [1876] 1947.

—, La justicia. Buenos Aires. Atalaya, 1947. 
Tennekes, J., Anthropology, relativism and method. An Inquiry into the Methodological Principles of a Science of Culture. Assen, Van Gorcum \& Co., 1971.

Tylor, Edward B., Cultura primitiva. Madrid: Ayuso, [1871] 1977.

—, Antropología. Introducción al estudio del hombre y la civilización. Barcelona: Editorial Alta Fulla, [1881] 1987.

VArga, Cisaba, "Teorías macrosociológicas del Derecho", Anuario de Filosofia del Derecho V, 1988: 23-53.

Wisler, Clark, Man and Culture. New York: Thomas Y. Crowell, [1923] 1965. 